\title{
The Role of Community in Disaster Response: Conceptual Models
}

\author{
Olivia Patterson · Frederick Weil · Kavita Patel
}

Received: 1 May 2007/ Accepted: 15 October 2008/Published online: 5 November 2009

(C) Springer Science+Business Media B.V. 2009

\begin{abstract}
We focus on the role that community plays in the continuum of disaster preparedness, response and recovery, and we explore where community fits in conceptual frameworks concerning disaster decision-making. We offer an overview of models developed in the literature as well as insights drawn from research related to Hurricane Katrina. Each model illustrates some aspect of the spectrum of disaster preparedness and recovery, beginning with risk perception and vulnerability assessments, and proceeding to notions of resiliency and capacity building. Concepts like social resilience are related to theories of "social capital," which stress the importance of social networks, reciprocity, and interpersonal trust. These allow individuals and groups to accomplish greater things than they could by their isolated efforts. We trace two contrasting notions of community to Tocqueville. On the one hand, community is simply an aggregation of individual persons, that is, a population. As individuals, they have only limited capacity to act effectively or make decisions for themselves, and they are strongly subject to administrative decisions that authorities impose on them. On the other hand, community is an autonomous actor, with its own interests, preferences, resources, and capabilities. This definition of community has also been embraced by community-based participatory researchers and has been thought to offer an approach that is more active and advocacy oriented. We conclude with a discussion of the strengths and weaknesses of community in disaster response and in disaster research.
\end{abstract}

Keywords Community - Disaster - Risk perception - Social capital · Vulnerability

O. Patterson $\cdot$ K. Patel $(\bowtie)$

the RAND Corporation, 1776 Main St, Santa Monica, CA 90402, USA

e-mail: Kavita321@yahoo.com

F. Weil

Department of Sociology, Louisiana State University, Baton Rouge, LA 70803, USA

e-mail: fweil@1su.edu 


\section{Introduction}

People make decisions every day, but decision-making in a natural disaster is unique and has great implications for individuals, communities and society at large. Hurricane Katrina clearly demonstrated the need for sound planning, swift execution and efficient accountability; but ultimately the negative consequences people experienced in this (as in any) disaster were conditioned by their perceptions of risk and their vulnerability, and how these factors influenced their ability to make and carry out decisions (Anderson-Berry 2003).

Aldunate and colleagues postulate that the quality of decision-making improves if the right people interact about the right tasks at the right time and with the right information (Aldunate et al. 2005). While this proposition forms a good starting point for understanding how people make choices in the face of risk, chances are good that each of these conditions will likely not be met in any one given situation.

Most decisions are the products of complex interactions between individuals, their communities, their surroundings and the natural environment itself. For example, in a random sample of evacuees surveyed immediately after Hurricane Katrina, the majority of evacuees stated that although they had previously experienced a significant hurricane before, they still felt that they lacked the appropriate information to make a decision to evacuate when a mandatory evacuation order was issued by local officials (Patel and Lurie, submitted and under review). This finding reveals that their perception of risk might have been correlated with the information conveyed as well as trust in authorities (e.g. less trust in order leads to a different decision). Dow and Cutter investigated the same phenomenon in communities affected by hurricanes in South Carolina and labeled it the "Crying Wolf syndrome", referring to an evacuation order for a storm that misses, which revealed a considerable degree of consistency in evacuation behavior despite a dramatic difference in the severity of storms (Dow and Cutter 1998).

So what explains this behavior? Why do some people, despite being presented with the same facts and compelling forces of nature, respond differently? In order to answer these questions and their implications, we must take a closer look at the factors that influence a decision. In particular, perceived risk by an individual or community has been thought to be a major component of decision-making.

Perceived risk is generally defined as consisting of two components: one's assessment of a natural hazard and one's vulnerability. The assessment of a natural hazard generally has to do with physical attributes such as the individual's shelter, distance from projected point of impact, structural integrity of safety mechanisms such as levees, etc. Vulnerability is largely defined as the "capacity to anticipate, cope with, resist and recover from the impact of a natural hazard" (Blaikie et al. 1994). Influences on risk perception can be thought of as protective or inhibitory. Protective factors include a supportive social network, increased resources (financial, intellectual) and household preparedness (Cutter and Emrich 2006; Johnston et al. 2005; Peacock et al. 2005; Anderson-Berry 2003). Taken together, these dimensions have a large effect on vulnerability, since vulnerability exists in equilibrium with these largely protective and inhibitory factors. 
So if the goal of disaster preparedness is to maximize beneficial decision-making under sub-optimal conditions, then whatever influences risk perception will have great impact. One of the emerging lessons in the immediate and long-term aftermath of Hurricane Katrina has been the role that community organizations and community-based networks played in all stages of disaster preparedness and recovery. The many community and faith-based organizations have consistently been on the ground early and remained in the forefront of the recovery effort, along with larger volunteer organizations like the American Red Cross. Observers have frequently pointed out that local faith-based, volunteer, nongovernmental organizations have been much more flexible and adaptive in the work of recovery (Appleseed 2006).

Analysts who approach disaster preparedness and recovery from a "top-down" managerial, policy, or planning perspective generally acknowledge that intangible social phenomena like "resilience" play a major role, but they often find them hard to explain. Yet concepts like social resilience have a long history in social theory. Much current work on "social capital" stresses the importance of social networks, reciprocity, and interpersonal trust, which allow individuals and groups to accomplish greater things than they could by their isolated efforts (Sampson et al. 2005; Putnam and Feldstein 2003; Lin et al. 2001; Putnam 2000; Coleman 1990). Earlier, related, work on democracy and political participation stress the importance of community, religion, family, social organizations - namely, civil society - in promoting the selfrestraint that makes democratic government and a free-market economy possible (Skocpol et al. 2000; Skocpol and Fiorina 1999; Greeley 1997; Verba et al. 1995; Weil 1994; Weil 1989; Lipset 1981; Verba and Nie 1972). These ideas can be traced back to the Federalist Papers, Adam Smith, John Locke, and earlier. They probably come together most fully in the first empirical and theoretical accounts of modern democratic society by Alexis de Tocqueville (de Tocqueville 2001, 2000).

In Tocqueville's view, free citizens who act together in community-using institutions of civil society like churches, voluntary associations, the press, and so on-are able to take immediate action to address issues that face them. They do not wait for a higher authority to solve problems for them, but rather, join together in addressing them themselves. They do not neglect self-interest; rather, it is moderated by a regard for the common good. In contrast, subjects of a despotic government are like children clamoring for hand-outs from the authorities, and squabbling with each other. Each person regards only his or her own self-interest and is jealous of what anyone else gets. As a result, they are incapable of cooperating or acting for themselves and must wait for government to help them. While few observers believe that the contrasts are as stark as Tocqueville paints them, or that a central authority is ever entirely absent or unnecessary, most modern theories of community or collective action accept the basic outlines of this account.

Indeed, Tocqueville's distinctions help shed light on two contrasting notions of community. On the one hand, community is sometimes treated simply as an aggregation of individual persons, that is, as a population. While the population may be discussed in small geographical units labeled neighborhoods, and while the population may be analyzed according to the individual traits of its membersincome, education, gender, race/ethnicity, religious denomination, and the like - and 
while these entities may be called "communities," they remain essentially aggregations of individuals. And as individuals, they have only limited capacity to act effectively or make decisions for themselves, and they are strongly subject to administrative decisions that authorities impose on them.

By contrast, a second notion treats community as an autonomous actor, with its own interests, preferences, resources, and capabilities. Of course, communities are themselves composed of individual persons - but this is a truism of only limited utility in this context. Even the highly individualistic Anglo-American legal tradition has long recognized the "fiction" of a corporation as a legal "person" that is capable of autonomous action, distinct from that of its owners or members. In his discussion of American civil society, Tocqueville points out that corporate actors like churches, clubs and associations, town meetings, political parties, and the like, are capable of the same great accomplishments that the aristocrats of feudal society once achieved, even in the face of a powerful central administration. And just as Adam Smith argued that private corporations are more efficient than government planning because they have local knowledge, so Tocqueville argued that community organizations are more effective than agents of central government-more flexible, adaptive, rapid, thorough, and consistent-not only because they have local knowledge, but also because they have an interest in a common good, of which a central government and its atomized, self-interested individual petitioners are incapable. This definition of community has also been embraced by communitybased participatory researchers and has been thought to offer an approach that is more active and advocacy-oriented (http://www.niehs.nih.gov/translat/cbpr/ cbpr.htm). This definition is also important for developing strategies for recovery and preparedness because it illuminates the relationship between organizations, individuals and government.

In this article, we focus on the role that community-or civil society-plays in the continuum of disaster preparedness, response and recovery, and we explore where community fits in conceptual frameworks concerning disaster decisionmaking. By highlighting several important conceptual models that currently exist in the literature, we hope that scientists, policymakers and other stakeholders can determine an appropriate role of communities in the process of preparedness and recovery. By highlighting the role of communities and the effect of a community on perceptions of risk and decision making in a natural disaster, scientists can properly develop and/or augment models of risk-perception, recovery and disaster preparedness.

We begin by offering a brief overview of some of the models developed in the literature as well as some insights drawn from research related to Hurricane Katrina. We selected particular models which are well suited to illustrate the importance of the inclusion of communities in the decision making framework for disaster preparedness and response. Each model illustrates some aspect of the spectrum of disaster preparedness and recovery, beginning with risk perception and vulnerability assessments, and proceeding to notions of resiliency and capacity building. In each model, we orient the reader towards the context in which the model was prepared as well as some of the appropriate applications for the integration of communities into the model. These models offer insight into the research to date as well as provide 
opportunities for adoption of the models with a community perspective and community-based participatory research. Next, we offer examples of how certain communities were able to act autonomously and interact with the government through the strengths of their solidarity, leadership and organization before, during and after Hurricane Katrina.

We close with some recommendations for future directions in the research to develop more conceptual constructs around communities and their role in preparedness, evacuation and recovery.

\section{Overview of Models}

\section{Models of Risk Perception and Vulnerability}

The first model from Smit and Wandel is one which incorporates the community in identifying risk and vulnerability in current and future situations (Smit and Wandel 2006; Fig. 1). Stakeholder and community engagement is highlighted in the model as a point of emphasis and as a means of improving "adaptive capacity." Adaptive capacity refers to the collective adaptability, coping capacity and resilience of a population. Smit refers to this framework as a "bottom-up" approach, involving key community stakeholders in a process to implement changes that are relevant to the community (Smit and Wandel 2006).

In addition, the framework calls for identifying current exposures, sensitivities and future adaptive capacity to understand issues a particular community might be confronted with and then employing various ethnographic methods to operationalize the constructs in the model. Such data collection has the advantage of qualitatively illustrating the complex interaction between communities and risk perception and decision-making.

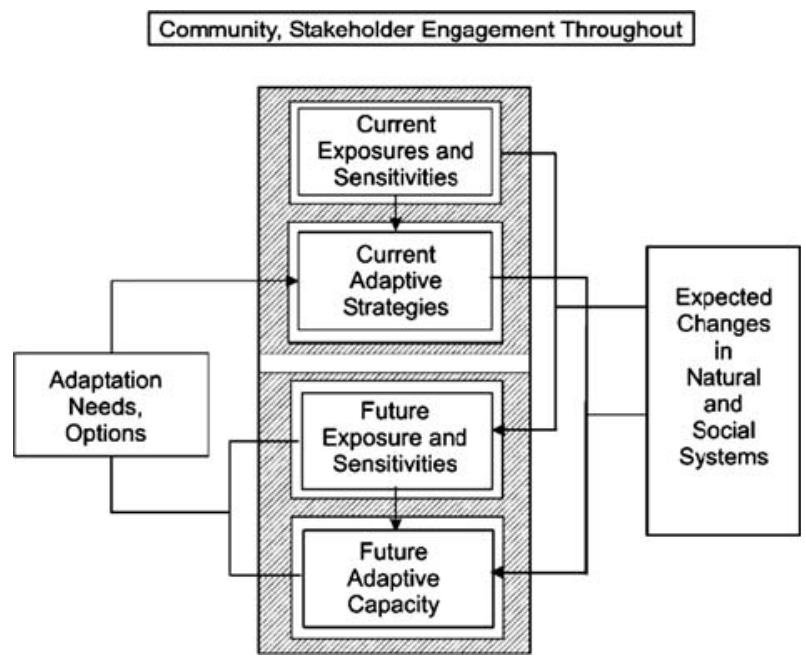

Fig. 1 Conceptual framework for vulnerability assessment and mainstreaming (Smit and Wandel 2006) 
In addition, implementation of any strategy for enhancing adaptive capacity should involve key stakeholders, decision makers and community members, as the adoption of increased adaptive capacity is determined by the cultural appropriateness and relevancy to the community members of these changes.

Another often-cited model which addresses vulnerability has been developed by Cutter and Emrich (2006). In their work, social and demographic vulnerability is tied to geographic vulnerability in the Social Vulnerability Index (SOVI). The index is defined as "the susceptibility of social groups to the impacts of hazards, as well as their resiliency, or ability to adequately recover from them" (Cutter and Emrich 2006, p. 103). The model also identifies the concept of place vulnerability which is made up of two main components: physical/environmental component and individuals' contextual characteristics. Through the identification of social and place vulnerability, the authors provide a conceptualization of the connection between these two concepts in the setting of risk perception.

Chen's model for integrating community-based disaster management (ICBDM) (see Fig. 2) offers a direct model of a community's role in (Chen and Chan 2006) risk perception and disaster preparedness.

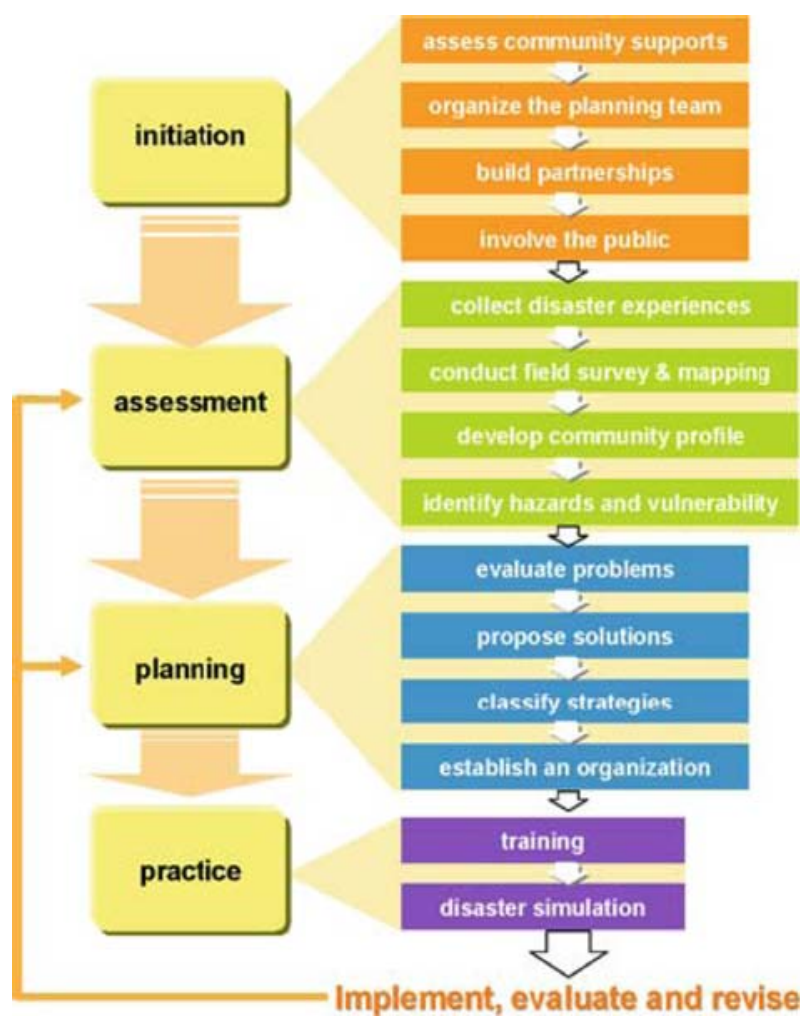

Fig. 2 Phased approach of ICBDM project (Chen et al. 2006, p. 220) 
This model incorporated a variety of phased steps including the establishment of a community-based disaster management organization, and final presentation. Chen highlights the importance of the participants (interested community members) of defining their own goals and strategies for disaster mitigation. In the first phase "initiation," community develops their own assessment through their previous experiences of natural disasters. Taiwan is a region that is prone to multiple natural disasters and identifying risks through previous experience can be protective or inhibitory according to current research. If there is a "crying wolf" effect, the participant tends to downplay future warnings, whereas if there is a significant event where there is damage to life or property, these individuals will likely have higher risk preparation and risk perception. In the remaining stages of the model, community participants identify problems and develop solutions, as well as identify responsibilities for managing disasters (e.g. which groups, household, community, or government, are responsible for which tasks). Chen's work is exceptional, as most community integrating models seek to employ the resources of the community for the response or aftermath of a disaster, but not for the initial planning phases. Instead, Chen postulates that if a community can strengthen its cohesion (thus mimicking the first notion of community posited by Tocqueville), than perhaps communities can play a key role in the implementation disaster preparedness programs (this is similar to Smit's idea of mainstreaming).

Ultimately each of these conceptual models offer a framework upon which evacuation behavior and action during a disaster might be influenced. Models of evacuation and action also have some variance of community cited with opportunity for an expansion of current models to include the notion of evacuation as a community action

\section{Model of Evacuation and Action}

Dash and Gladwin provide a comprehensive framework for evacuation as a function of individual factors, event characteristics and risk perception (Fig. 3; Dash and Gladwin 2005). Through the deconstruction of the action of evacuation, Dash illustrates that risk perception is made up of a variety of elements that vary by individual and community, including; socioeconomic factors, experience factors, trust of authorities, storm knowledge, home characteristics, and message dissemination. These variables interact with each other to either enhance or reduce risk perception. Dash and Gladwin's approach is to organize the factors involved in decision-making, understand how information is used, and determine what influences individual action.

In contrast to Smit's model, Dash offers a guide for the components of individual action and eventually evacuation which we postulate are closely tied to their communities. In the context of Katrina, individual action was largely dependent on the factors that Dash outlines but these factors are also influenced by the communities of the survivors as well. We discuss examples of these processes in more detail below. 


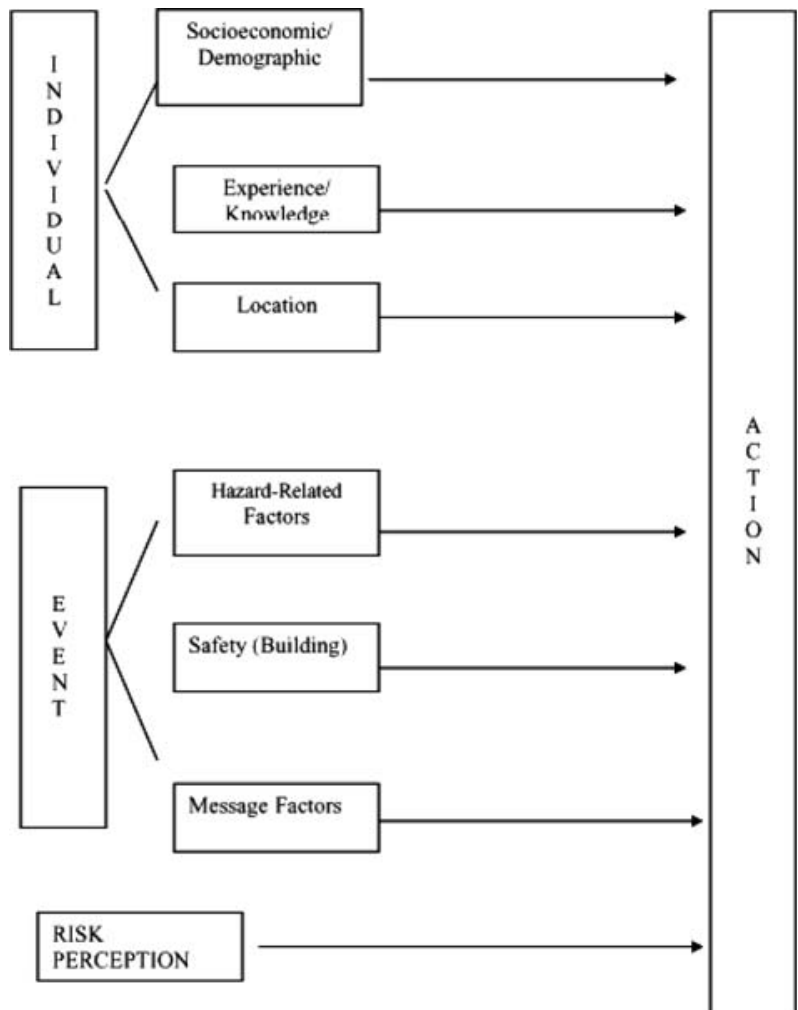

Fig. 3 Basic model of evacuation (Dash and Gladwin 2005, p. 6)

\section{Models of Disaster Recovery}

The dimension of recovery after a disaster is probably the one that has been the most studied and offers the most comprehensive conceptual models related to the roles of stakeholders at all levels. The first model of disaster recovery that we highlight is from Lemyre et al. and draws upon a body of knowledge from the fields of psychology and sociology (Lemyre et al. 2005). Lemyre et al conceptualize the management and assessment of psychosocial needs after a disaster and offer a model which centers on the notion of a community as a resource, similar in fashion to the adaptive capacity described by Smit and Wandel (Fig. 1; Cutter and Emrich 2006; Norris et al. 2005). Lemyre et al.'s model is called a Psychosocial Risk Assessment and Management Framework Development Process (PRAM) and illustrates the integration of community members and other relevant stakeholders in the psychosocial aftermath of a disaster (see Fig. 4).

The following processes comprise the PRAM framework: identification of the issue and the context, assessment of risks and benefits, identification and analysis of options, strategy selection and implementation and finally, result evaluation. The interested and affected parties should be involved throughout this process and just as 


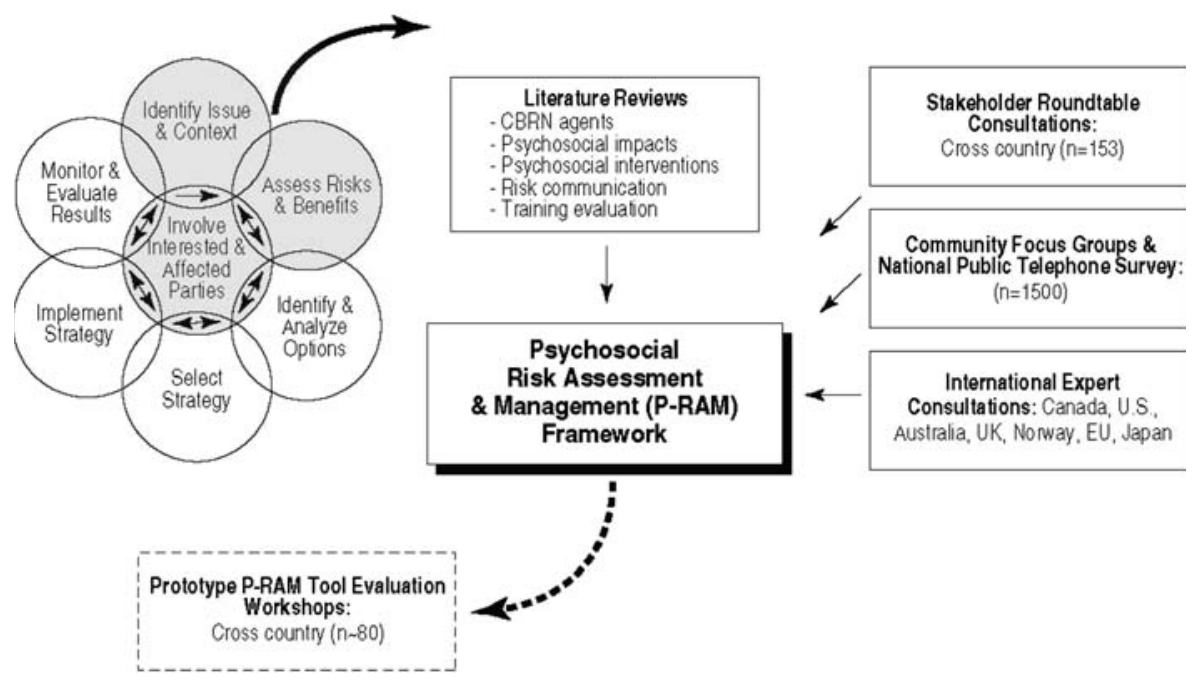

Fig. 4 Psychosocial Risk Assessment and Management Framework (Level 1) (Lemyre et al. 2005, p. 319)

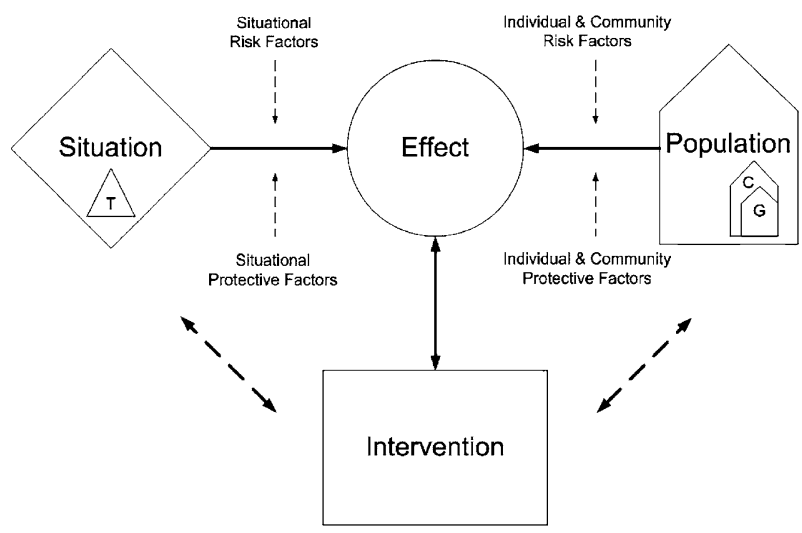

Fig. 5 CBRN Psychosocial Risk Assessment and Management Framework (Level 1) (Lemyre et al. 2005, p. 322)

Smit posits, Lemyre also proposes that the community is one of the most central parties and key stakeholders.

As a complement to the development process, Lemyre also provides a model for the results of this development process. The CBRN Psychosocial Risk Assessment and Management Framework (see Fig. 5) emphasizes the "dynamic interaction between features of the individual, community, and society, and characteristics of the disaster event itself as mediators of psychosocial stress responses to a crisis event."(Lemyre et al. 2005, p. 321). Lemyre's framework highlights the importance of viewing a disaster event (and in the context of Katrina, the preparation for the event) as part of the community and social context. 
Ultimately, the main use of Lemyre's PRAM and CBRN frameworks are to conceptualize the factors involved in developing intervention programs for psychosocial risk after disasters. One of the most important concepts is resiliency which is also critical to disaster preparedness. According to Lemyre, "the process of resilience is facilitated by the presence of protective factors at the individual, family, and community levels that serve to mitigate the impacts of adversity and strengthen community capacity to deal with existing and future events."(Lemyre et al. 2005, p. 319). Finally, we return to Chen et al. to highlight a conceptual model which integrates risk perception, vulnerability, evacuation/action and disaster response and recovery (Chen et al. 2006).

Integrating Communities into all Aspects of Disasters

Chen's model for potential partners of the ICBDM (Integrated Community-Based Disaster Management) project is a model for how a community based disaster management program will function prior to, during and after a disaster (see Fig. 6).

This is an important model for community integration into the planning and response processes. From viewing this model, it appears that the following items are important to think about prior to initiating a disaster management project: how would a community working group be selected and by whom? Are there gaps between experts and community inhabitants? One limitation of the ICBDM model is that is not entirely clear whether communities consist of autonomous actors or are simply local administrative units of a central authority. He appears to lean toward autonomy. If this is the case, then his model opens a large number of pertinent questions about the relations between community and government: to what extent is this a true partnership, and how is it structured? We return to some of these questions in the discussion section below.

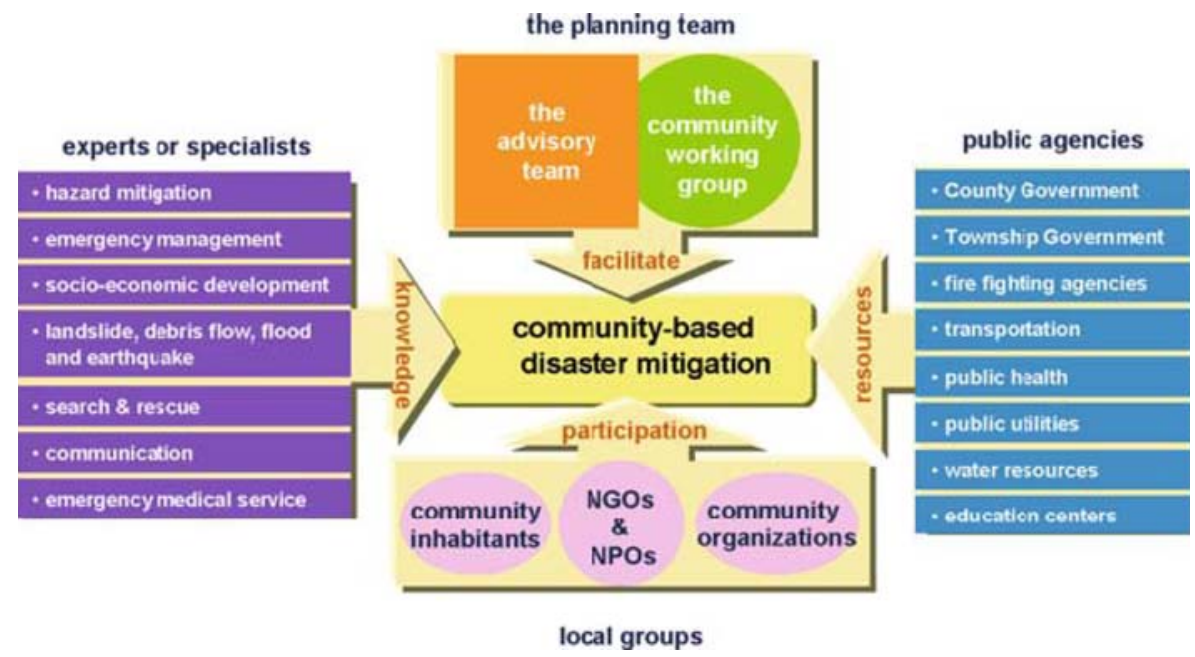

Fig. 6 Potential partners of ICBDM project (Chen et al. 2006, p. 221) 


\section{Examples of Community's Role in and after Hurricane Katrina}

Community responses to Hurricane Katrina demonstrate the importance of local knowledge, resources, and cooperative strategies in determining their survival and recovery, that is, their resilience. These responses can also greatly inform theories and practice of disaster preparedness and risk perception planning, and help us see better how communities' strengths and capabilities can be integrated into these processes. In this section, we present some examples of the social learning that is taking place in various communities in the aftermath of Hurricane Katrina, in the areas of preparedness, response and relief, and recovery.

\section{Preparedness}

A number of examples and best practices were re-examined and re-applied in the Gulf Coast region after the experiences of Hurricane Katrina. For instance, the Jewish communities of southern Louisiana have adopted contingency planning methods developed by Jewish Family Service (JFS) agencies in southern Florida, which has also experienced many hurricanes. Florida's JFS compiled an Emergency Care Contact List, for which senior citizens could voluntarily pre-enroll. Then, in the event of a hurricane, JFS has the ability to deliver services and assistance to seniors who are known to be potentially vulnerable (Leeds 2006).

\section{Evacuation, Rescue, and Relief}

The Coast Guard, National Guard, trained and licensed first responders, and heroic individuals were not the only agents of effective emergency aid, rescue, and relief. Community, faith-based, and nonprofit organizations, too, immediately applied their preexisting organizational skills and capabilities, and stepped into the breach.

The leadership of the Vietnamese community in New Orleans East followed a strikingly effective, strategy. As it became known that Katrina presented the city with imminent danger, the community evacuated everyone who would leave and alerted Vietnamese communities in the surrounding areas that they would be coming. Community members arrived at local Vietnamese shopping centers, and local community members came out and indicated how many evacuees they could house. Meanwhile, community leaders remained in New Orleans during the storm and subsequent flood, tending to community members in need. As soon as they were able, community leaders drove around the region with digital cameras and laptop computers, taking pictures of community members and showing them to separated loved ones, assuring them that they were safe (Pope 2006; Rev. Nguyen 2006; Cohen 2005).

\section{Recovery}

As soon as the water had been drained from their neighborhood, the Vietnamese community returned and began rebuilding. They warehoused building materials in the church, worked together to repair damaged houses, one by one, starting from the 
roofs down, and cooked and ate as a community. At first, the city and utility companies declined to reconnect water and electric service, but Church leaders collected hundreds of signatures to prove that community members were back in residence, and successfully pressed for re-establishment of services. Within about a half-year, the community had repaired and re-occupied much of its damaged housing, and resumed long-term planning, which was already underway prior to the storm, for a retirement center, a community garden and a farmers' market, pausing along the way to successfully block a landfill uncomfortably near their neighborhood. When asked how they had accomplished so much with so few material resources, Fr. Nguyen The Vien answered, "Other people have neighborhoods, we have a community" (Gold 2006; Strange 2006; Rev. Nguyen 2006; Hauser 2005).

In Baton Rouge, the closest large place of refuge, fully half or more of the residents had spontaneously housed evacuees and volunteered for relief work (Weil et al. 2006; Editorial 2005; Kern 2005). A large, informal, loosely structured, interdenominational group of faith leaders was immediately called into being and began meeting weekly, continuing to present day. Several hundred participants have taken part in the meetings, helping organize immediate relief, create case management programs, collect and distribute information, coordinate congregational efforts, and develop longterm disaster contingency and recovery plans (Weil as participant-observer). Community, faith-based, and nonprofit organizations have been so centrally involved in long and short-term recovery efforts, illustrating the importance of communities in the conceptualization of the entire spectrum of disaster planning and management.

\section{Discussion}

Hurricane Katrina has caused our entire nation to pause and re-examine our own capacity to deal with a disaster. The models we have highlighted each offer a different perspective on the conceptual framework that underlies the capacity to prepare for, act during and recover after a disaster. Each model also has some aspect of a community involved in the process, with Chen's models offering what we feel is the most comprehensive incorporation of community by illustrating the benefit of bringing community members into each aspect of disaster management. In particular, the Integrated Community-Based Disaster Management (ICBDM) model is closely aligned with our experience after Katrina with regard to the roles of community organizations and NGOs in general.

But not every community is equal and not all communities are beneficial. The strengths and weaknesses of community must be taken into account. On the positive side, well functioning community organizations have the trust of their members and possess the moral authority to urge cooperative behavior and teamwork that government lacks. They also have strong abilities to assess needs and distribute goods and services efficiently and equitably. Thus, observers often stress the importance of including communities in disaster response and creating meaningful partnerships between communities and government agencies. 
However, communities have weaknesses, too. For instance, partnership with government may neutralize community's potential benefits. Government funding or pre-certification could undermine the independence and autonomy of community organizations - and along with that, their moral authority over, and loyalty of, their members (Pipa et al. 2006). Cain and Barthelemy (2008) note that every church in their Baton Rouge study but one declined government reimbursement for the expenses they incurred in their relief work.

Communities may also play a role that is detrimental to their members or to society at large. For example community cohesion in disaster response may encourage members to remain in vulnerable locations because they have a false sense of security or desire to maintain community solidarity. Certain shared practices, beliefs, etc, may lead communities \& their members to act in ways that make them more vulnerable. Communities may also act in an exclusionary fashion with respect to non-community members. They may attempt to monopolize resources, information, access, etc, for their own members and exclude others.

Finally, there are methodological challenges in operationalizing community variables in empirical research. Inequality is generally easier to measure than is social capital or group solidarity. For instance, in discussing the "architecture of entitlements" that determine the resilience and vulnerability of a community, Kelly notes that "...there is a danger that those factors that can be easily incorporated in a composite index [of vulnerability], such as poverty, will be over-emphasized as factors such as institutional adaptation that, although no less important, cannot be as readily quantified are neglected" (Kelly and Adger 2000, p. 331).

In conclusion, we highlight models which incorporate communities in the spectrum of dealing with disasters because throughout history, communities and their organizations have played very significant roles. Each of the models we highlight also serves as a foundation for further empirical research. Some important questions that should be addressed include: what is the applicability of the model to different disasters and populations? Who is the community and how is it defined? Nevertheless, the experiences of Hurricane Katrina bring researchers, policymakers and other relevant stakeholders to pause and consider a broader model that incorporates true partnerships with communities.

Acknowledgement This material is based upon work supported by the National Science Foundation under Weil Grant No.0554572 and Patel Grant \#: 0601731.

\section{References}

Aldunate, R. G., Pena-Mora, F., \& Robinson, G. E. (2005). Collaborative distributed decision making for large scale disaster relief operations: Drawing analogies from robust natural systems. Complexity, $11(2), 28-38$.

Anderson-Berry, L. (2003). Community vulnerability to tropical cyclones: Cairns, 1996-2000. Natural Hazards, 30(2), 209-232.

Appleseed. (2006). A continuing storm: The on-going struggles of Hurricane Katrina evacuees. Retrieved December 18, 2006, from http://www.appleseeds.net/servlet/PublicationInfo?articleId=207.

Blaikie, P., Cannon, T., Davis, I., \& Wisner, B. (1994). At risk: Natural hazards, peoples vulnerability and disasters. London: Routledge. 
Cain, D. S., \& Barthelemy, J. (2008). Tangible and Spiritual Relief after the Storm: The Religious Communities Response to Katrina Community. Journal of Social Service Research , 34(3), $29-42$.

Chen, L. C., Liu, Y. C., \& Chan, K. C. (2006). Integrated community-based disaster management program in Taiwan: A case study of Shang-An Village. Natural Hazards, 37(1-2), 209-223.

Cohen, S. (2005). Vietnamese priest works to rebuild his flooded parish. New York: Associated Press.

Coleman, J. S. (1990). Foundations of social theory. Cambridge: The Belknap Press of Harvard University Press.

Cutter, S. L., \& Emrich, C. T. (2006). Moral hazard, social catastrophy: The changing face of vulnerability along the hurricane coasts. The Annals of the American Academy, 604, 102-112.

Dash, N., \& Gladwin, H. (2005). Evacuation decision making and behavioral responses: Individual and household. Pomona, CA: Hurricane Forecast Socioeconomic Workshop.

de Tocqueville, A. (2000). Democracy in America. Chicago: University of Chicago Press.

de Tocqueville, A. (2001). The old regime and the revolution. Chicago: University of Chicago Press.

Dow, K., \& Cutter, S. L. (1998). Crying wolf: Repeat responses to hurricane evacuation orders. Coastal Management, 26, 237-252.

Editorial. (2005, December 29). Helping others during storms.Baton Rouge Advocate.

Gold, S. (2006, February 26). In New Orleans, home is still far away. Half a year after Katrina ravaged the city, most residents haven't returned. And those who have remain in a state of uncertainty. Los Angeles Times.

Greeley, A. (1997). The other civic America: Religion and social capital. American Prospect, 32, 68-73.

Hauser, C. (2005, October 20). Sustained by close ties, Vietnamese toil to rebuild. New York Times.

Johnston, D., Paton, D., Crawford, G. L., Ronan, K., Houghton, B., \& Burgelt, P. (2005). Measuring tsunami preparedness in coastal Washington, United States. Natural Hazards, 35, 173-184.

Kelly, P. M., \& Adger, W. N. (2000). Theory and practice in assessing vulnerability to climate change and facilitating adaptation. Climatic Change, 47, 325-352.

Kern, E. (2005). More than half of EBR residents aided evacuees. Baton Rouge Advocate Study.

Leeds, M. (2006, June 9). Ruth Rales Jewish Family Service prepares pre-enrollment hurricane emergency care contact list. Press release by the Ruth Rales Jewish Family Service of South Palm Beach County.

Lemyre, L., Clement, M., Corneil, W., Craig, L., Boutette, P., Tyshenko, M., et al. (2005). A psychosocial risk assessment and management framework to enhance response to CBRN terrorism threats and attacks. Biosecurity and Bioterroris: Biodefense Strategy, Practice and Science, 3(4), 316-330.

Lin, N., Cook, K., \& Burt, R. S. (Eds.). (2001). Social capital. Theory and research. New York: Aldine De Gruyter.

Lipset, S. M. (1981). Political man (2nd ed.). Baltimore: Johns Hopkins University Press.

Norris, F. H., Baker, C. K., Murphy, A. D., \& Kaniasty, K. (2005). Social support mobilization and deterioration after Mexico's 1999 flood: Effects of context, gender, and time. American Journal of Community Psychology, 36(1-2), 15-28.

Patel, K., \& Lurie, N. (submitted and under review). Effect of pre-existing health status on evacuation timing in Hurricane Katrina.

Peacock, W. G., Brody, S. D., \& Highfield, W. (2005). Hurricane risk perceptions among Florida's single family homeowners. Landscape and Urban Planning, 73(2-3), 120-135.

Pipa, T., Costanza, T., Thomas, D., \& Haley, M. (2006, November 3). Research, service delivery strategies, best practices: Disaster mitigation. Paper presented at the translating research into action: Nonprofits and the renaissance of New Orleans, New Orleans.

Pope, J. (2006). East N.O. priest personifies resilience. Vietnamese leader preaches self-reliance. New Orleans Times-Picayune.

Putnam, R. D. (2000). Bowling alone: The collapse and revival of American community. New York: Simon \& Schuster.

Putnam, R. D., \& Feldstein, L. M. (Eds.). (2003). Better together: Restoring the American community. New York: Simon \& Schuster.

Rev. Nguyen, V. (2006). Interviews with Frederick Weil, at Mary Queen of Vietnam Catholic Church, 5069 Willowbrook Dr., New Orleans, LA 70129. April 22, May 14, June 6, September 9, October 23.

Sampson, R. J., MacIndoe, H., McAdam, D., \& Weffer-Elizondo, S. (2005). Civil society reconsidered: The durable nature and community structure of collective civic action. American Journal of Sociology, 111(3), 673-714. 
Skocpol, T., \& Fiorina, M. P. (1999). Civic engagement in american democracy. Washington, DC, New York: Brookings Institution Press, Russell Sage Foundation.

Skocpol, T., Ganz, M., \& Munson, Z. (2000). A nation of organizers: The institutional origins of civic voluntarism in the United States. The American Political Science Review, 94, 527-546.

Smit, B., \& Wandel, J. (2006). Adaptation, adaptive capacity and vulnerability. Global Environmental Change - Human and Policy Dimensions, 16(3), 282-292.

Strange, P. (2006, August 29). Strength to lead the charge. The parishioners of Mary Queen of Vietnam Church in eastern New Orleans have faced their share of obstacles since Hurricane Katrina, but with every new challenge, they are proving 24 that swift action might be the best weapon in the fight to rebuild. New Orleans Times-Picayune.

Verba, S., \& Nie, N. (1972). Participation in America. New York: Harper and Row.

Verba, S., Schlozman, K. L., \& Brady, H. E. (1995). Voice and equality: Civic voluntarism in American politics. Cambridge: Harvard University Press.

Weil, F. D. (1989). The sources and structure of legitimation in Western democracies: A consolidated model tested with time-series data in six countries since World War II. American Sociological Review, 54(5), 682-706.

Weil, F. D. (1994). Political Culture, political structure and democracy: The case of legitimation and opposition structure. In F. D. Weil (Ed.), Research on democracy and society, political culture and political structure: Theoretical and empirical studies (Vol. 2, pp. 65-116). Greenwich, CT: JAI Press.

Weil, F., Shihadeh, E., \& Lee, M. R. (2006). Hurricane Katrina related research. New Orleans, LA: Southern Sociological Society Annual Meetings. 